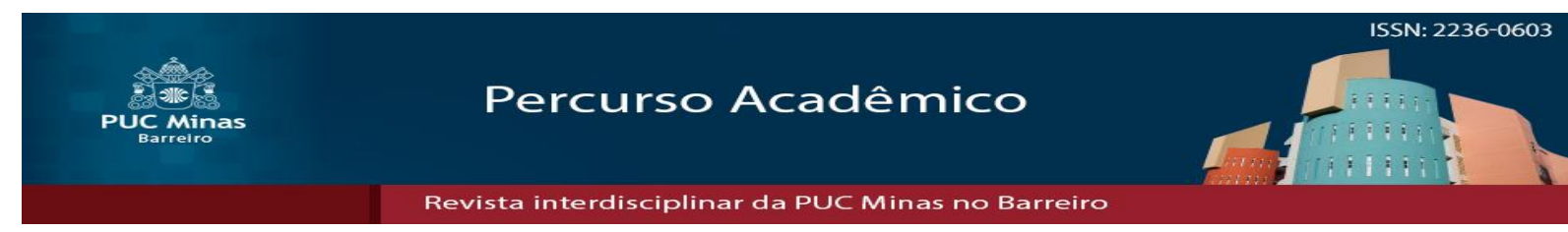

\title{
As estratégias da prevenção do crime através do desenho urbano - ambiental (CPTED) como alternativas à questão da arquitetura do medo
}

\author{
The crime prevention strategies through urban - environmental design (CPTED) \\ how alternatives to the question of the fear architecture
}

\author{
Mariana Cezar Gonçalves ${ }^{1}$ \\ Jáfia Quaresma Pinto
}

Pablo Silva Lira $^{3}$

\begin{abstract}
Resumo
O presente estudo traz um comparativo em torno da problemática da criminalidade violenta e seu papel na modificação da arquitetura em dois bairros localizados em cidades distintas, porém com adversidades semelhantes: Bento Ferreira em Vitória-ES e Santo Antônio dos Prazeres-BA. A interpretação das relações de materialização e forma que cada comunidade desenvolve para tentar mitigar o medo da violência urbana é fundamental para compreender as soluções encontradas por regiões distintas à mesma diversidade. Partimos da premissa de que a violência urbana está influenciando as formas e construção da cidade, sobretudo, nos espaços residenciais. A análise desenvolvida é baseada nos perfis socioeconômicos e variáveis importantes de ambas as localidades aqui discriminadas, juntamente com o mapeamento e levantamento fotográfico, que são imprescindíveis para a caracterização da configuração espacial e identificação das inserções de dispositivos de autoproteção utilizados pelos habitantes dos bairros, para garantir segurança que acabam por modificar a paisagem urbana existente. A partir do estudo desenvolvido é possível compreender preliminarmente os principais fatores que influenciam de forma recíproca a relação cidade/violência.
\end{abstract}

Palavras-chaves: Arquitetura do medo. Bento Ferreira. Santo Antônio dos Prazeres.

\begin{abstract}
This study presents a comparative study about the problem of violent crime and its role in modifying the architecture in two districts located in different cities, but with similar adversities: Bento Ferreira in Vitória - ES and Santo Antônio dos Prazeres - BA. The interpretation of the relations of materialization and form that each community develops to try to mitigate the fear of urban violence is fundamental to understand the solutions found by different regions of the same diversity. We start from the premise that urban violence is influencing the forms and construction of the city, especially in residential spaces. The analysis developed is based on the socioeconomic profiles and important variables of both locations, together with the photographic mapping, which are essential for the characterization of the spatial configuration and identification of the insertions of selfprotection devices used by the inhabitants of the neighborhoods, to guarantee security that End up modifying the existing urban landscape. From the study developed, it is possible to understand the effects caused by the city / violence relationship, in order to address actions that may mitigate the impacts caused by fear in urban morphology.
\end{abstract}

Keywords: Architecture of Fear. Bento Ferreira. Santo Antônio dos Prazeres.

\footnotetext{
${ }^{1}$ Graduada em Arquitetura e Urbanismo pela Universidade Vila Velha e Bolsista de Iniciação Científica financiada pela Universidade Vila Velha (UVV). E-mail: marianacezarg@gmail.com

${ }^{2}$ Graduanda em Arquitetura e Urbanismo pela Universidade Vila Velha e Bolsista de Iniciação Científica financiada pela Universidade Vila Velha (UVV). E-mail: jafiapinto13@hotmail.com

${ }^{3}$ Professor do Mestrado em Segurança Pública e da Graduação de Arquitetura e Urbanismo da Universidade Vila Velha (UVV). E-mail: pabloslira@gmail.com
} 


\section{Introdução}

A problemática da criminalidade violenta é diagnosticada em diversas regiões do país, tornando-se um assunto pertinente sobre as configurações espaciais e aspectos que influenciam no cotidiano das pessoas e na arquitetura, transformando as paisagens das cidades, sob a perspectiva da arquitetura do medo. (LIRA, 2014).

A combinação entre medo, violência e diversidade social está ligada à segregação espacial existente nas cidades, visto que, ao considerar determinados grupos como potenciais criminosos, a necessidade de se distanciar e se diferenciar desses grupos engendra o processo de segregação, tornando as cidades mais ociosas e propícias a ocorrências de crimes. Caldeira (2000) trata a relação da criminalidade violenta em São Paulo com as transformações espaciais, a partir do olhar dos moradores diante da necessidade de associar os altos índices de criminalidade na região em estudo a determinados grupos sociais e ao crescimento desordenado com a falta de planejamento, tendo em vista a alta densidade demográfica que a região adquiriu.

Em contrapartida a privatização da segurança e enclausuramento das elites surgem como opções para tornar as residências mais seguras, reproduzindo nas cidades aspectos dos fortes imperiais, ou os chamados enclaves fortificados. (CALDEIRA, 2000). Os elementos de autoproteção, cercas elétricas, concertinas (rolos de arame farpado), arames, cacos de vidro e câmeras de videomonitoramento, que são utilizados nas residências, configuram bem o que é aqui abordado, quando o indivíduo se vê impulsionado a se prevenir e distanciar dos espaços públicos, indo na contrapartida do que Jacobs (2000) aborda, quando a necessidade da permeabilidade visual o "ver e ser visto" se torna fator importante contra a prevenção de crimes, sobretudo, delitos contra o patrimônio.

Nessa perspectiva, este estudo desenvolve uma análise comparativa entre as cidades de Vitória - ES e Feira de Santana - BA. De acordo com os dados do Censo IBGE (2010), o município de Vitória possui cerca 327 mil habitantes e constitui a capital do estado do Espírito Santo e a principal centralidade da Região Metropolitana da Grande Vitória (RMGV). Com base nessa mesma fonte de dados, constata-se que o município de Feira de Santana possui cerca de 557 mil habitantes (IBGE, 2010) e constitui a principal centralidade da Região Metropolitana de Feira de Santana (RMFS).

Além de possuir uma população relativamente próxima e também constituírem a principal centralidade de suas Regiões Metropolitanas (RMs), essas duas cidades são classificadas na pesquisa "Regiões de Influência das Cidades - REGIC" como Capitais Regionais (IBGE, 2007). Inicialmente, pretendia-se estudar comparativamente espaços dos municípios de Vitória - ES e Salvador - BA por serem cidades capitais. Todavia, existe uma grande diferença demográfica entre essas duas capitais. A população de Salvador - BA, no Censo de 2010, era de aproximadamente 2,6 milhões de habitantes. Nesse sentido, a opção pela análise comparativa entre espaços de Vitória - ES e Feira de Santana - BA se justifica mais pela semelhança demográfica. Os espaços pesquisados nesses dois últimos municípios foram os bairros de Bento Ferreira, em Vitória - ES, o bairro Santo Antônio dos Prazeres, em 
Feira de Santana - BA. Esses bairros enfrentam problemas relacionados à criminalidade violenta em diferentes nuanças.

O bairro Bento Ferreira, Vitória - ES possui grande interesse por parte de imobiliárias, devido sua capacidade de atrair investimentos e potencial construtivo, sendo objetivo de grandes massas demográficas que veem adensando a região e modificando a paisagem com suas inserções. Essa dinâmica está intensificando o aumento de ocorrências de roubos no bairro de Bento Ferreira. (LIRA, 2014). O outro bairro em análise, Santo Antônio dos Prazeres, localizado em Feira de Santana - BA, possui taxas crescentes de crimes de roubos. Embora não seja um dos bairros com os maiores registros de crimes violentos contra a pessoa em sua RM, Santo Antônio dos Prazeres é considerado local onde é procedida a desova de corpos de vítimas de homicídios que geralmente ocorrem no bairro vizinho, Conceição. O bairro Conceição possui altos índices de criminalidade contra a pessoa, com isso o os moradores do bairro Santo Antônio dos Prazeres, vem modificando a arquitetura, devido ao medo. (SANTOS NETO, 2016).

O presente trabalho se propõe a analisar e comparar as formas de autoproteção referentes ao espaço urbano sob a perspectiva do Crime Prevention Through Environmental Design (CPTED), do bairro Bento Ferreira em Vitória - ES e Santo Antônio dos Prazeres em Feira de Santana - BA, a fim de discutir as semelhanças e diferenças da problemática da criminalidade violenta em cidades com infraestruturas e configurações demográficas e urbanas próximas.

A criminalidade violenta interpessoal (homicídios, roubos, sequestros, entre outros) vem preocupando os habitantes das cidades contemporâneas devido ao seu crescente índice, induzindo os moradores a se adaptarem a nova realidade do cotidiano, causando segregação e uma nova configuração espacial através de artefatos de autoproteção. Em contrapartida a Arquitetura é considerada a principal ferramenta no desenvolvimento e planejamento do espaço urbano.

Com a necessidade da adaptação dos espaços ao fator da criminalidade, as características da arquitetura veem modificando com o passar dos anos. Existem estudos acerca da relação entre a criminalidade violenta e as inserções de dispositivos de segurança que causam a sensação de tranquilidade e paz entre moradores de cidades contemporâneas. O presente estudo analisa e justifica a importância da arquitetura, que possui seu papel de grande responsabilidade no planejamento sobre as relações entre as pessoas e a cidade, principalmente em bairros como Bento Ferreira e Santo Antônio dos Prazeres. Os bairros em questão apresentam índices de criminalidade elevados, tornando possível a integração da arquitetura aos espaços públicos e residências, que devem ser estudados de modo a possibilitarem novas formas de prevenção à criminalidade.

\section{Metodologia}

Este estudo tem como base a metodologia qualitativa que surge a partir de pesquisas bibliográficas em livros e artigos científicos sobre a temática da criminalidade urbana violenta, 
que são norteadas, sobretudo, pelas seguintes referências: "A geografia do Crime, Arquitetura do Medo" (LIRA, 2014), "Cidade de Muros: Crime, Segregação e Cidadania em São Paulo" (CALDEIRA, 2000), "Morte e Vida nas Grandes Cidades" (JACOBS, 2000) e " Prevenção do Crime através do Desenho Urbano" (BONDARUK, 2007), sendo possível através desses um aprofundamento teórico e posteriormente uma contextualização das questões abordadas nesta pesquisa.

A direção inicial deste estudo esteve subvencionada no desenvolvimento de outra pesquisa referente às questões socioeconômicas do último censo, 2010, para maior entendimento da distribuição geográfica das informações censitárias nos bairros do munícipio de Vitória - ES, consequentemente Bento Ferreira. Variáveis socioeconômicas, como: níveis de instrução, renda média salarial e características dos domicílios, foram coletadas e subsequentemente submetidas aos tratamentos estatísticos necessários para o cálculo de percentuais, taxas e índices.

As referências aqui citadas são de suma importância, pois a partir delas foram qualificadas questões como a arquitetura do medo, as paisagens do medo e suas representações no espaço urbano e no dia-a-dia das pessoas, entendendo assim de que forma a população tende a responder quando se sente insegura e busca encontrar a melhor solução. (LIRA, 2014).

Citando também Jacobs (2000) em sua seminal obra "Morte e Vida nas Grandes Cidades" que associa a problemática da falta de vitalidade urbana com os espaços ociosos e estimula a diversidade de usos e conexão visual entre a rua e as edificações, como alguns dos fatores primordiais para fazer das cidades, cidades mais vivas, analisando assim as situações contemporâneas que estão ocorrendo nelas.

Caldeira (2000) trata em sua obra "Cidade de Muros: Crime, Segregação e Cidadania em São Paulo", as transformações socioespaciais justificadas pelo medo da violência, em São Paulo; as estratégias capazes de reestruturar os espaços residenciais das cidades, tornando-os controlados pela comunidade. Estes métodos englobam barreiras simbólicas ou reais, áreas de influência fortemente definidas e o aumento das oportunidades de vigilância, tudo articulado para criar um espaço capaz de ser controlado pelos seus residentes. (NEWMAN, 1996).

Nesse sentido, este trabalho busca estabelecer um olhar comparativo entre Bento Ferreira (Vitória - ES) e Santo Antônio dos Prazeres (Feira de Santana - BA), a partir dos referenciais teóricos mencionados, para identificar os principais padrões do desenho urbano e da arquitetura do medo, bem como as potencialidades e adversidades das estratégias de inibição do cometimento de crimes via intervenções arquitetônicas e urbanísticas. Insta reforçar que as cidades estudadas encontram-se em contextos geográficos distintos. A primeira, a capital capixaba, possui mais de 325 mil habitantes e situa-se na Região Sudeste; e a segunda, uma cidade com mais de 550 mil habitantes, localizada na Região Nordeste. (IBGE, 2010). Porém, essas duas cidades apresentam características demográficas semelhantes e problemas relacionados à incidência de crimes, sobretudo, os delitos contra o patrimônio. (LIRA, 2014; SANTOS NETO, 2016). 
Além disso, as pesquisas de Lira (2014), Lyra et al. (2015) e Santos Neto (2016) serviram de base para contextualizar e caracterizar os elementos da Arquitetura do Medo e do CPTED por meio de seus acervos fotográficos e análises sobre, respectivamente, Bento Ferreira (Vitória - ES) e Santo Antônio dos Prazeres (Feira de Santana - BA).

\section{Embasamento teórico}

A temática da violência vem sendo abordada há longos tempos por diversos autores, que desenvolvem estudos norteadores a novas discussões como Jacobs (2000), Caldeira (2000), Bondaruk (2007) e Lira (2014) mostrando que a problemática em questão é vivenciada em diversas cidades.

Caldeira (2000) cita em seu livro "Cidade de muros: crime, segregação e cidadania em São Paulo" a relação entre o homem e o espaço como principais difusores para as novas configurações espaciais e o quanto as cidades se modificam diante de fatores como o medo e a violência.

Assim como Caldeira (2000), a análise sobre os dados socioeconômicos se faz presente em ambos os bairros em estudo, buscando o entendimento da ligação entre a imagem que a cidade transmite e o que é vivenciado pelos moradores. Jacobs (2000) analisa aspectos que podem vir a modificar e favorecer a segurança nos espaços, como a vigilância natural, pouco difundida em espaços seguros, que é quando existe a permeabilidade visual entre espaços privados e públicos permitindo ao transeunte a possibilidade de garantir a sensação de segurança das pessoas ao serem observadas, ou na linguagem da autora o "ver e ser visto", isto é, potencialização da vigilância natural.

No contexto brasileiro, por meio de uma ampla pesquisa com internos de unidades prisionais do estado do Paraná, Bondaruk (2007) pondera determinadas ações e estratégias que possuem o intuito de eliminar as características físicas de ambientes que facilitam o delito. Ele cita estratégias que atuariam como preventores de crimes, sendo eles: a vigilância natural, pois de acordo com os dados, os locais que ocorrem mais delitos são lugares que, geralmente, têm menor tráfego são mais escuros, possuem obstáculos que dificultam a visão de vizinhos, dentre outros; o controle de acesso é a forma como é pré-estabelecido o controle de entrada e a permanência de pessoas em determinado ambiente e o reforço territorial é o instinto natural de se ter determinado espaço como domínio pessoal.

Analisando as cidades capixabas, Lira (2014) desenvolve um campo de pesquisa que traduz uma compreensão mais ampla das questões centrais da sociedade brasileira. Perspectivas espaciais, geográficas, demográficas e socioeconômicas da violência são associadas ao urbano que a partir de dados sobre Vitória, que refletem nas estratégias de políticas públicas preventivas o desencadear do medo existente na população. (LIRA, 2014).

\section{Arquitetura do medo}

Em certa medida, privação de liberdade, que Foucault (1987) chama de "obviedade" permite comparar as reais prisões com as quais se vive hoje, ou seja, os espaços residenciais, 
especialmente. É cada vez mais comum achar métodos de autoproteção equivalentes aos utilizados em arquitetura de presídios que condicionam ao autoenclausuramento e o autoconfinamento dos moradores. A arquitetura das grandes cidades brasileiras tende cada vez mais a se auto proteger e nota-se que estas características ficam mais semelhantes às de um presídio, uma vez que incorporam elementos para conter as invasões devido ao pânico que vem sendo potencializado pelo crescimento da criminalidade violenta e o fortalecimento da cultura do medo. (CALDEIRA, 2000).

O medo do crime é transferido para as formas das habitações e de certo modo para a própria cidade, despertando um novo rearranjo na morfologia urbana, como as "paisagens do medo" vem sendo configuradas e novos padrões de sociabilidade desenvolvidos. (LIRA, 2014).

O “medo social", de acordo com Lira (2014), está relacionado ao fenômeno da violência caracterizando-se como um sentimento coletivo, vivenciado por todos. Mesmo sendo o medo construído de forma individual pelos humanos, a sociedade compartilha do sentimento de impotência referente ao aumento da criminalidade violenta, favorecendo o também aumento de um dos principais medos urbanos, medo de ser vítima de algum tipo de violência. (LIRA, 2014).

Entretanto, a abordagem midiática utiliza o medo potencial da violência, fazendo valer por meio de especulação, frequência e repetição, para despargir e potencializar a cultura do medo. Os meios de comunicação, sendo quaisquer deles, são caminhos potencializadores do medo nas cidades, tracejando uma conjuntura de pânico polarizado que acaba direcionando para práticas individualistas, intolerantes e segregatórias.

\footnotetext{
Cotidianamente, a mídia se lança na corrida pela confecção de manchetes alarmantes que pouco favorecem o debate coerente acerca de possíveis soluções para o problema em questão, mas nutrem substancialmente o processo de espetacularização da violência e os temores dos cidadãos em habitar as "fobópoles" brasileiras. (LIRA, 2014, p.132).
}

Além dos fatores supracitados fortalecedores da imagem do medo do crime, a indústria imobiliária e a de segurança privada estão vinculadas diretamente com o aumento e conservação do pânico relacionado à violência urbana para alcançar, cada vez mais, rendimentos lucrativos. Analisando os fatos é factível dizer que os equipamentos de segurança começaram a ser instalados não somente por conta da violência, mas sim a um maior privilegio para os condomínios, permitindo que os grupos mais favorecidos sejam manipulados pelo discurso da segurança, almejando também uma separação e um distanciamento dos demais grupos sociais. (CALDEIRA, 2000).

Com isso, depara-se cada mais vez com uma arquitetura inibidora, que afasta, utilizando artefatos que segregam os espaços, tornando-os ociosos e sem vida ativa, criando uma utópica ideia de segurança.

Os novos sistemas de segurança não só oferecem proteção contra o crime, mas também criam espaços segregados nos quais a exclusão é cuidadosa e rigorosamente praticada. Eles asseguram "o direito de não ser incomodado", provavelmente uma alusão à vida na cidade e aos encontros nas ruas com pessoas de outros grupos sociais, mendigos e sem teto. (CALDEIRA, 2000, p. 267). 
Assim sendo, a representação da arquitetura do medo, aponta para uma nova vertente para as configurações espaciais da cidade, norteando os visuais e as características arquitetônicas e urbanísticas influenciadas pelo medo, podendo ser identificada em diversas cidades distintas, independente de características sociais ou econômicas.

Diante da arquitetura do medo e a necessidade pelo entendimento das novas formas arquitetônicas e urbanísticas, a terminologia CPTED - Crime Prevention Through Environmental Design (Prevenção do crime através do desenho urbano), foi muito utilizada nos EUA e difundida pelo criminologista Ray Jeffery na década de 70. Jeffery trouxe à tona a importância das discussões sobre os espaços públicos, partindo da premissa do olhar do criminoso as oportunidades da prática dos atos delituosos, analisando as principais características do espaço externo como ponto principal para a redução das chances para o cometimento de tal ato. O CPTED pode ser entendido como a prevenção do espaço construído através do desenho ambiental e resulta nos elementos entendidos como, vigilância natural; manutenção do espaço construído; territorialidade e controle natural de acesso.

A partir desses pontos podemos mitigar as ações remanescentes vividas pela sociedade, diante da insegurança existente nas cidades, independentemente de localização.

\section{CPTED e arquitetura do medo em Bento Ferreira}

O bairro Bento Ferreira, engloba a porção insular sul do município de Vitória, e fica localizado próximo a bairros desprivilegiados, sob a perspectiva socioeconômica (LIRA, 2014), como por exemplo, Jesus de Nazareth, Gurigica, dentre outros. (LIRA, 2014). Bento Ferreira é circundado por avenidas importantes da capital capixaba, como a Avenida Marechal Mascarenhas de Moraes (sentido leste-oeste), Avenida Vitória (sentido leste-oeste), Avenida Cesar Hilal (sentido leste-oeste) e Avenida Leitão da Silva (sentido norte-sul). Bento Ferreira é considerado um dos bairros mais privilegiados da região, devido seu potencial de verticalização, o que acaba aumentando o interesse imobiliário. Como um desdobramento desse processo recente, o bairro de Bento Ferreira passa por um acentuado adensamento populacional.

Figura 1: Localização da área de estudo no município

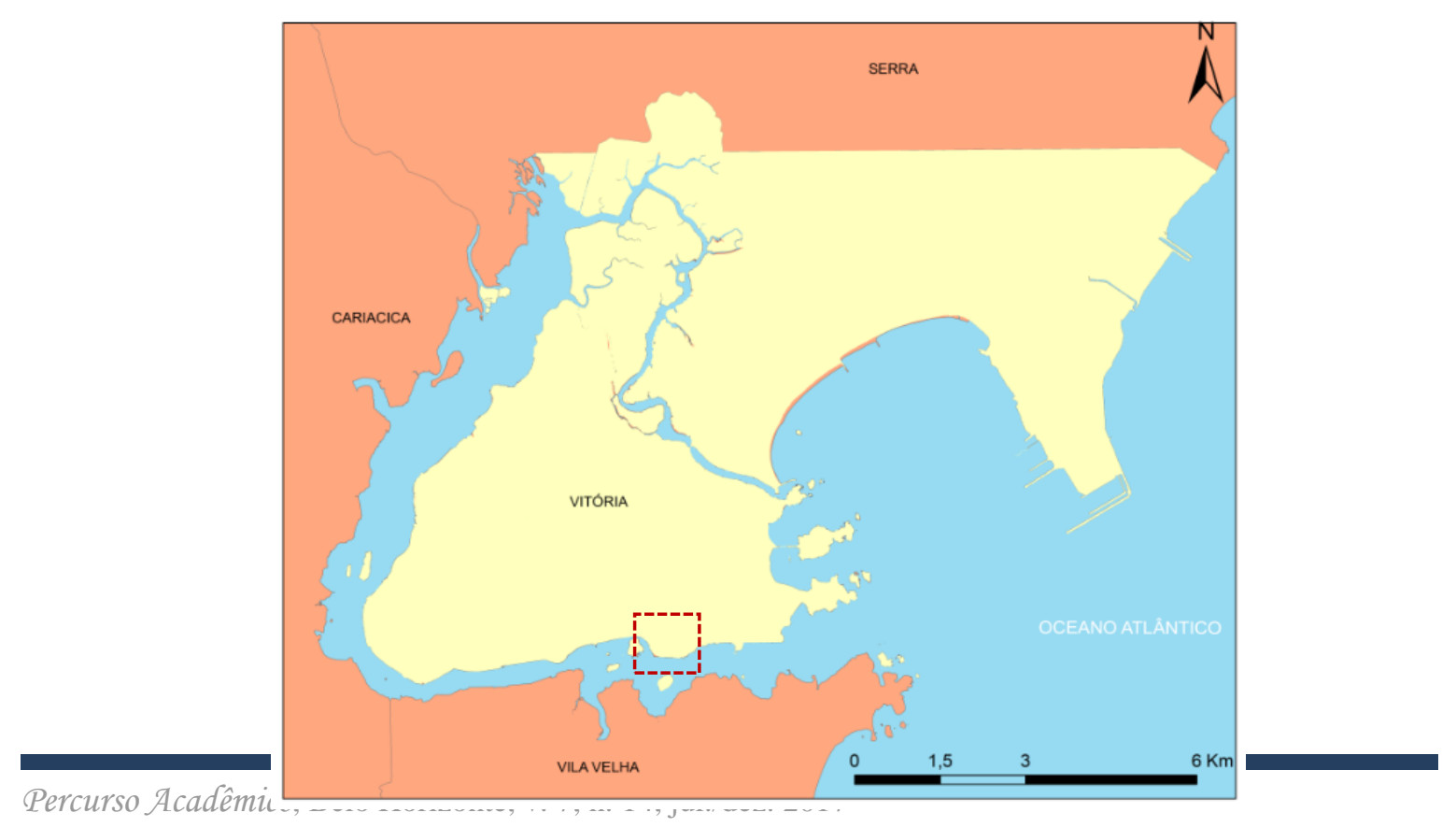


Fonte: Elaborado pela Autora , 2016

\section{Figura 2: Localização do Bento Ferreira e bairros vizinhos}

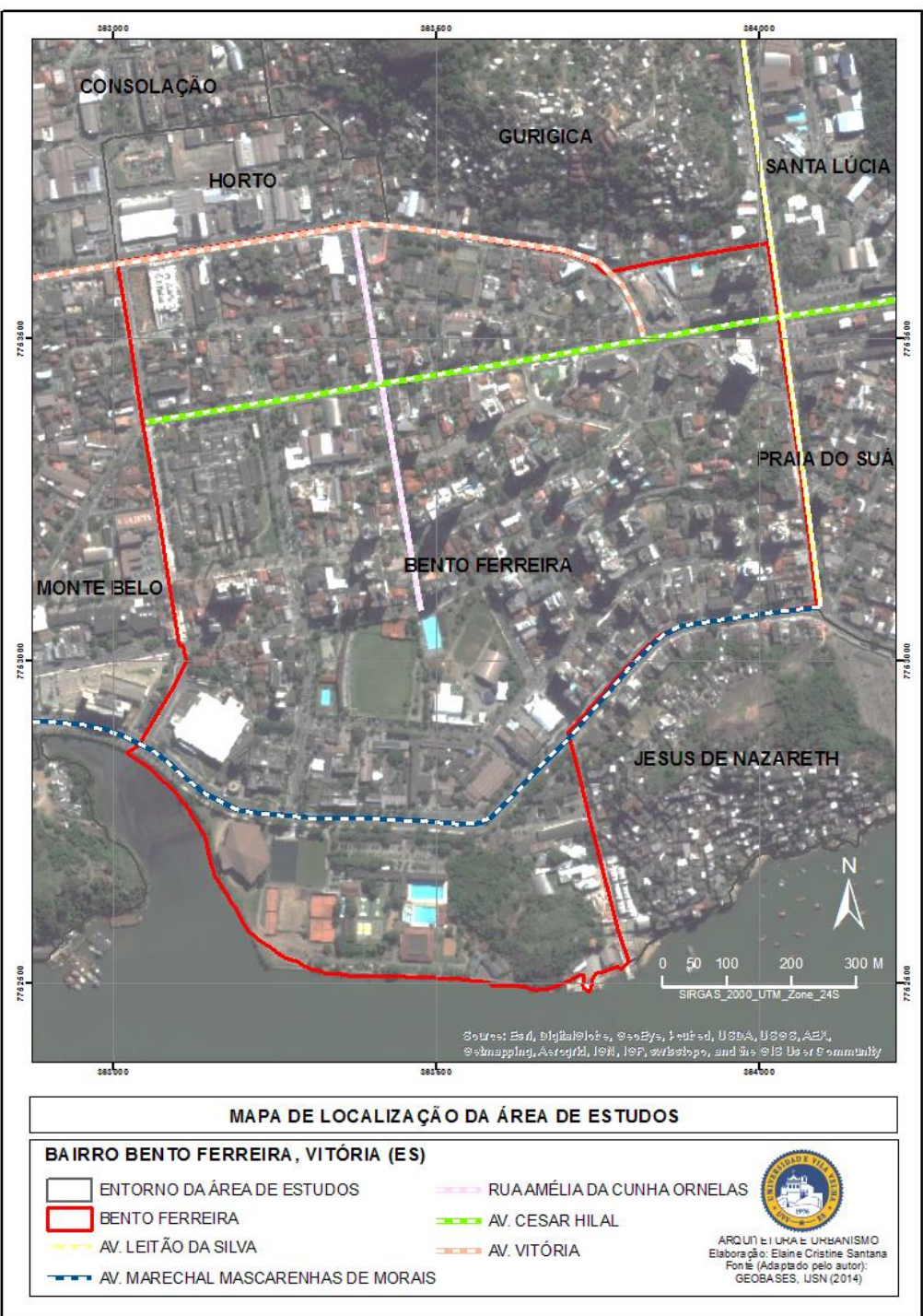

Fonte: Acervo Projeto de Pesquisa Análise Espacial dos Indicadores socioeconômicos no Bairro Bento Ferreira, Vitória - ES, 2015

A partir das configurações socioespaciais, a breve análise sobre a arquitetura do medo e as formas de prevenção do crime através do desenho urbano leva em consideração os elementos de autoproteção comerciais e principalmente residenciais, que modificam a paisagem da localidade, como justificativa ao medo pertinente.

A configuração da arquitetura do medo torna as cidades enclausuradas e segregadas através dessas modificações, quando há a necessidade de se proteger de atos criminosos, mas em contrapartida o indivíduo perde o contato com a rua, tornando as cidades mais ociosas e menos interessantes, não havendo interesse pelo que nos rodeia, sendo esse fator diagnosticado em Bento Ferreira e em outras tantas cidades e bairros.

Jacobs (2000) retrata a questão da vigilância natural, sob a perspectiva da vitalidade urbana, o "ver e ser visto", quanto maior for a diversificação de usos e funções da cidade, maior será o interesse em circular pelas ruas e interagir com o entorno, aumentando a sensação de segurança. Porém, o que vemos refletido nas cidades contemporâneas segue o caminho contrário. $\mathrm{Na}$ área de estudo foram identificados os mais diversos tipos de elementos utilizados 
para autoproteção, como: cercas elétricas, muros elevados, lanças, concertinas, que nos remetem à imagem dos enclaves fortificados (CALDEIRA, 2000) e elementos prisionais configurados para preservar a integridade da sociedade diante de ações criminosas.

Figura 3: Muros associados a lanças envolvendo condomínio residencial no bairro Bento Ferreira em 2015

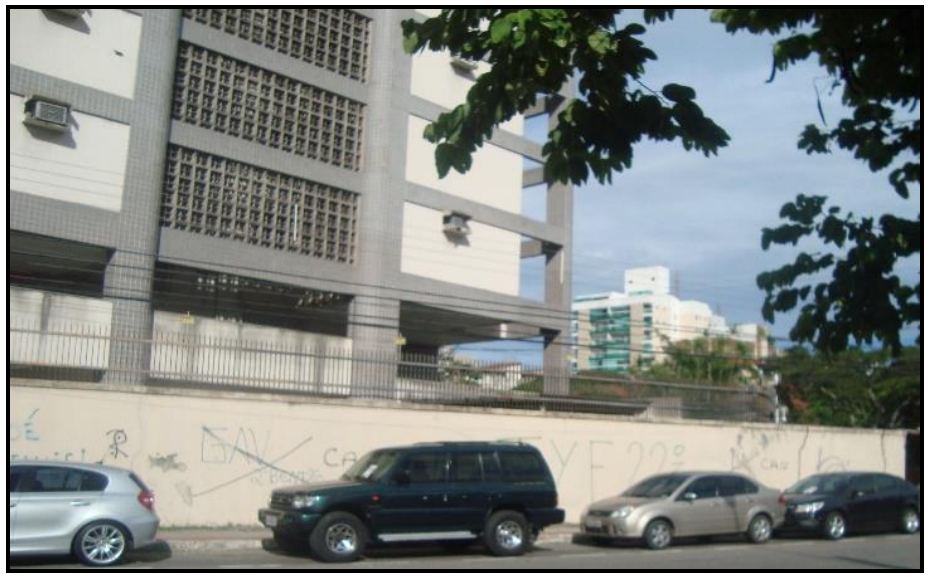

Fonte: Acervo Projeto de Pesquisa Análise Espacial dos Indicadores socioeconômicos no Bairro Bento Ferreira, Vitória - ES, Lyra et al., 2015

Figura 3 - Estabelecimento comercial envolto por muros no bairro Bento Ferreira em 2015

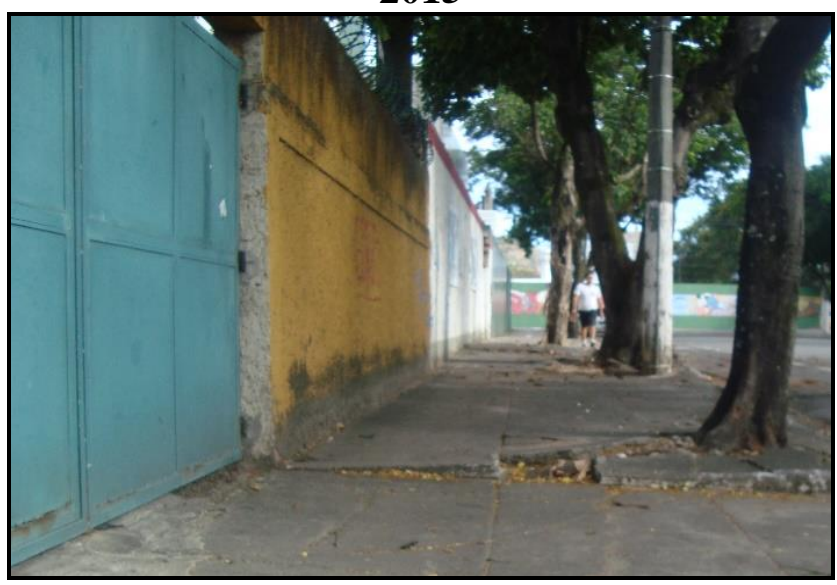

Fonte: Acervo Projeto de Pesquisa Análise Espacial dos Indicadores socioeconômicos no Bairro Bento Ferreira, Vitória - ES, Lyra et al., 2015

Em Bento Ferreira, os elementos citados anteriormente foram identificados em vários pontos do bairro, conforme Lira (2014) descreve em seu estudo sobre a arquitetura do medo e as paisagens do medo. Essas são fortemente configuradas e representadas nas imagens acima, sobre a percepção dos moradores aos espaços que vivem. Por meio das Figuras, aqui apresentadas, pode-se constatar a presença na maioria das residências e espaços comerciais, de algum tipo de elementos arquitetural de autoproteção ou a combinação desses.

Os muros altos, presentes na região em estudo, se configuram de representações vistas anteriormente na idade média, quando se criavam presídios afim de resguardar os cidadãos de malfeitores, porém, assim como visto nas Figuras 2, 3 e 5, o muro alto vem sendo utilizado nas cidades como forma de autoproteção e privando os espaços privados da vigilância natural empregada por Jacobs (2000), como um dos pontos primordiais para melhorar a vitalidade e uso dos espaços. 
Figura 4: Rolo de concertina duplo associado à tela de aço em residência no bairro Bento

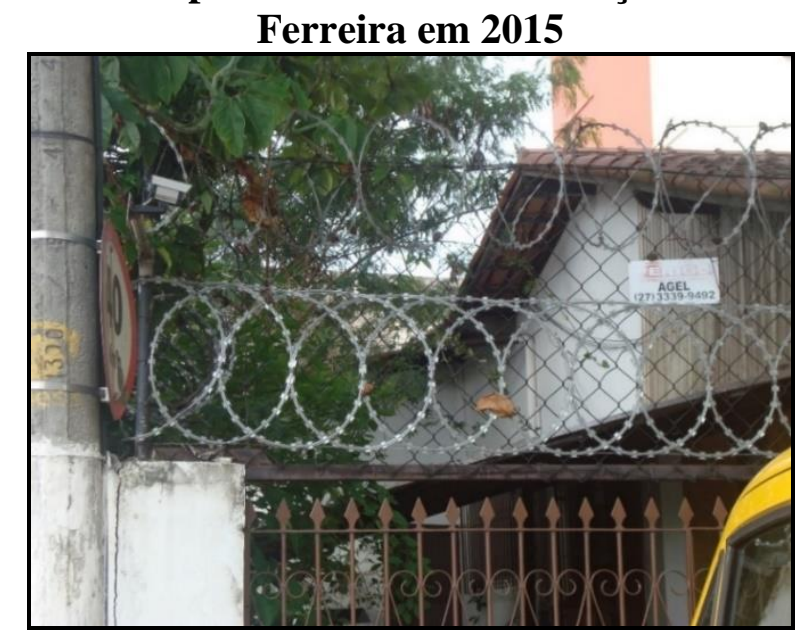

Fonte: Acervo Projeto de Pesquisa Análise Espacial dos Indicadores socioeconômicos no Bairro Bento Ferreira, Vitória - ES, Lyra et al., 2015

Figura 5: Muro alto combinado com rolo de concertina no bairro Bento Ferreira em 2015

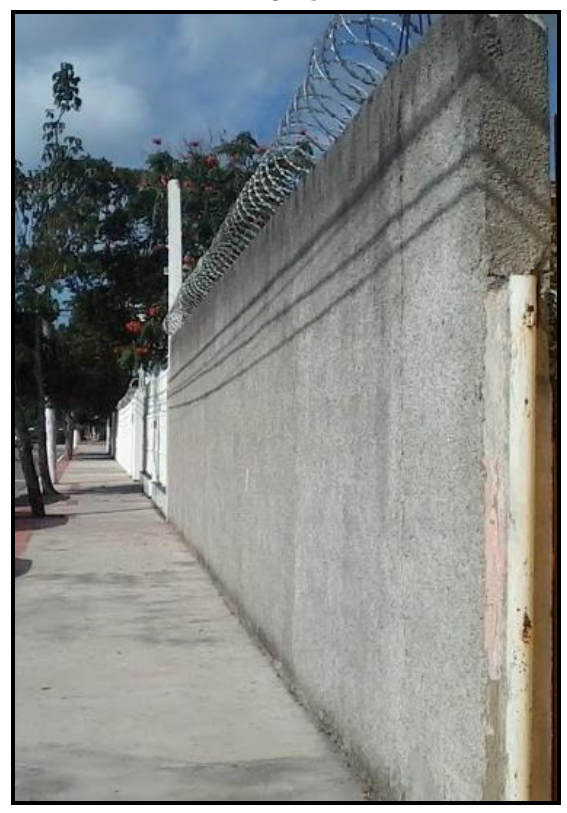

Fonte: Acervo Projeto de Pesquisa Análise Espacial dos Indicadores socioeconômicos no Bairro Bento Ferreira, Vitória - ES, Lyra et al., 2015

Atrelado ao muro alto, o rolo de concertina e a tela de aço, utilizados em comércios e residências (ver Figuras 4 e 5), surgem como opções para a prevenção e resguardo dos espaços privado. Essas combinações são muito utilizadas nas cidades atualmente e, também, se assemelham aos elementos utilizados em presídios.

Este não é um privilégio das cidades capixabas. Na verdade, pode ser entendido como um padrão e tendência da maioria das cidades brasileiras na contemporaneidade. Na próxima seção, analisaremos alguns resultados de uma pesquisa desenvolvida em uma cidade do nordeste do país, Feira de Santana - BA, com o objetivo de confirmar parcialmente a presença da arquitetura do medo naquele contexto.

\section{CPTED e arquitetura do medo em Santo Antônio dos Prazeres}

Santo Antônio dos Prazeres é um bairro situado em Feira de Santana no estado da Bahia, é subdistrito de Mangabeira e um dos bairros mais antigos do município. Faz divisa com os bairros 
Conceição, Aeroporto e Caseb, bairros consideravelmente perigosos, como aponta a pesquisa de Santos Neto (2016).

Figura 7: Localização do Bairro Santo Antônio dos Prazeres

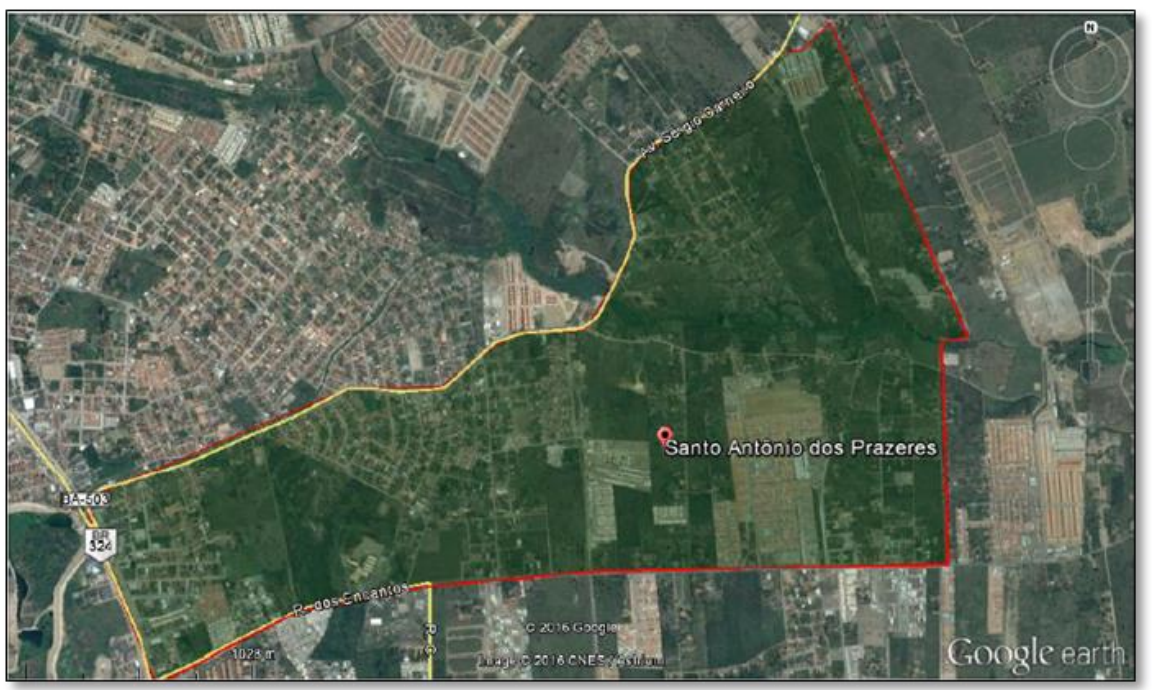

Fonte: Santos Neto, 2016

O estudo de Santos Neto (2016) indica que a criminalidade está presente na configuração urbana de Santo Antônio dos Prazeres - B. Mesmo esse bairro não sendo caracterizado como um espaço violento, na perspectiva dos crimes contra a pessoa, observouse um aumento do número de homicídios. Há relatos de que apesar dos crimes ocorrerem no bairro vizinho, Conceição, Santo Antônio dos Prazeres é destacado pelas estatísticas criminais, pois existe uma grande quantidade de corpos encontrados no bairro que atualmente ficou muito conhecido por ser local de desova.

A figura a seguir demonstra a predominância dos crimes dentro das principais ocorrências do bairro, ressaltando grandes números para furtos e roubos. Santos Neto (2016) pondera que em resposta essa criminalidade existente, as residências servem-se dos artifícios da "arquitetura do medo" como forma de proteção ao crime, assim como exposto acima na definição de CPTED e Arquitetura do Medo no bairro de Bento Ferreira. Esses elementos são traduzidos em forma de muros altos, grades com lanças, cercas elétricas, serpentinas etc., conforme apresentado nas imagens a seguir. 
Figura 8: Resumo das principais ocorrências policiais para o Bairro de Santo Antônio dos Prazeres nos anos de 2012 a 2014

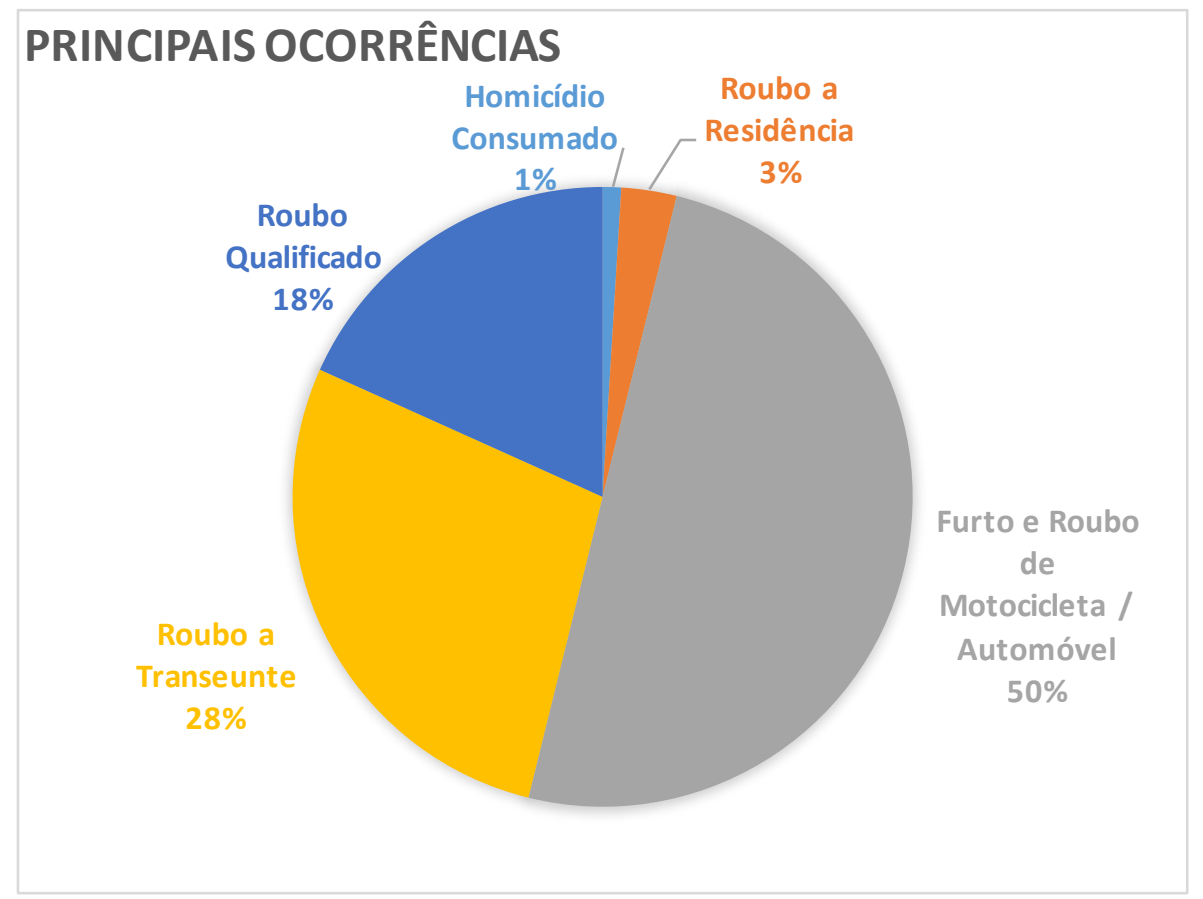

Fonte: Santos Neto, 2016

Figura 9: Arquitetura do Medo, serpentinas, muro alto no Bairro de Santo Antônio dos Prazeres em 2015

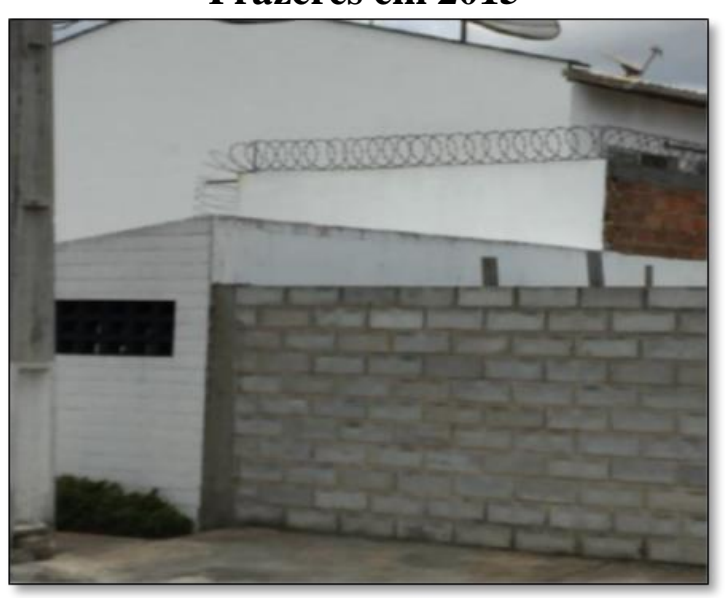

Fonte: Santos Neto, 2016

Figura 10 e 11: Arquitetura do Medo, muro alto no Bairro de Santo Antônio dos Prazeres em 2015

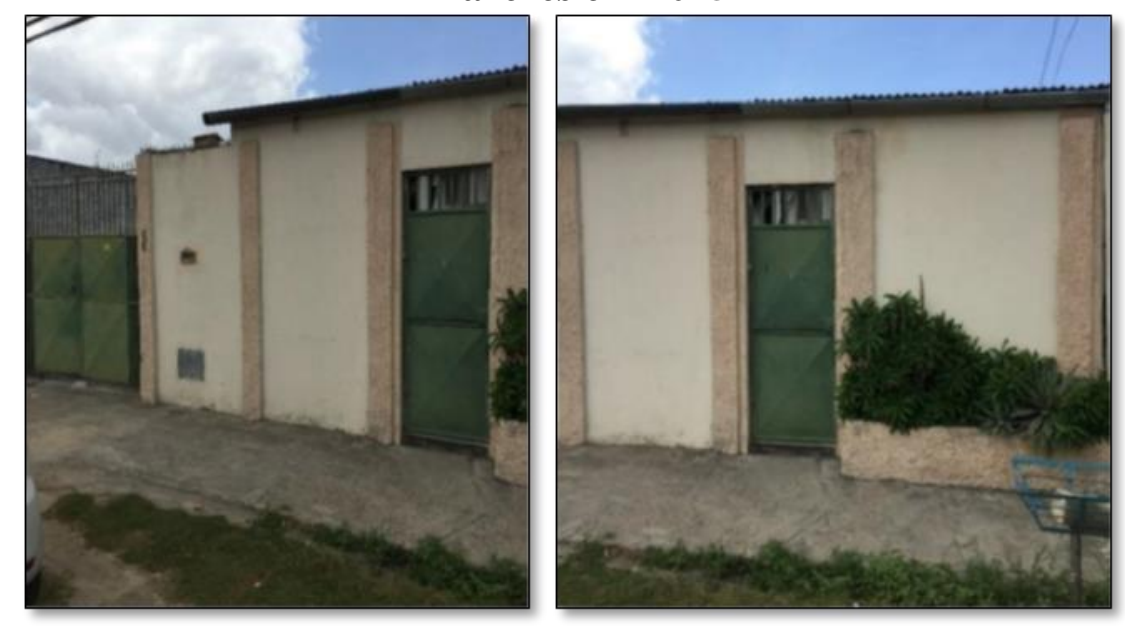

Fonte: Santos Neto, 2016 
No estudo de Santos Neto (2016) são apresentados exemplos de habitações onde se percebe a arquitetura equivalente aos presídios, utilizando concertinas, câmeras de videomonitoramento entre outros elementos de autoproteção, não havendo diálogo com as edificações circunvizinhas, além de contribuir para o esvaziamento das ruas de acesso, uma vez que, se tornam mais vulneráveis pela escassez de vigilância natural. (JACOBS, 2000). Com isso, é perceptível a clareza do enclausuramento do bairro e a inevitabilidade do morador em se isolar cada vez mais do entorno. A partir dessas reações enxerga-se a forte materialização da criminalidade violenta e a interferência dela no cotidiano da vida privada e pública, tanto humana quanto urbana, pois os dois lados são igualmente prejudicados.

Santos Neto (2016) também toma como referência Lira (2014) para descrever os padrões e tendências da arquitetura do medo no referido bairro do nordeste brasileiro.

\section{Considerações Finais}

Diante da análise aqui apresentada, identifica-se a multifacetada forma da arquitetura do medo, influenciada pelo fator que rodeia as decisões humanas nas cidades contemporâneas, o medo. As modificações feitas nas paisagens urbanas em função da delimitação do espaço e da criminalidade violenta demonstraram novos olhares aos estudos antes realizados baseados no Crime Prevention Through Environmental Design (CPTED), em localidades com índices significativos sobre criminalidade ao patrimônio.

Ao compararmos Bento Ferreira e Santo Antônio dos Prazeres, notamos bairros com configurações socioespaciais e dados socioeconômicos diferenciados, mas que discorrem sobre a mesma problemática encontrada em tantas cidades, que é a violência no espaço residencial. As medidas de solução para mitigar a criminalidade vivenciadas em ambos os bairros foram implementadas a partir do uso de elementos de autoproteção, que caracterizam ambientes cada vez mais enclausurados.

Mesmo não se revelando tão claramente nos bairros periféricos quanto nos bairros de médio e ou alto padrão, a cultura do medo atinge diversos tipos de classes sociais e pereniza cada vez mais, contaminando as pessoas. O bairro, bem como seus espaços públicos, fica relegado ao segundo plano diante do enclausuramento dos habitantes, que por conta do receio, segregam espaços públicos e privados e se veem desestimulados a comparecer e permanecer menos nas ruas, facilitando assim o surgimento de criminosos em praças, quadras, parques, visto que, se transformaram em locais abandonados ou pouco utilizados.

O processo de segregação das classes sociais menos privilegiadas, em função da cultura do medo, não ocorre apenas em algumas cidades. As formas de inserção dos elementos de autoproteção identificados configuram as modificações arquitetônicas e urbanísticas em ambos bairros aqui analisados, como reflexos de uma nova vertente da construção das cidades, configurando o medo como norteador importante das novas instalações da arquitetura contemporânea. 
Sendo assim, ressaltamos a presença, mesmo que parcialmente, da arquitetura do medo nos bairros que aqui foram analisados e percebemos como cidades distintas e em localidades distantes possuem a mesma preocupação sobre a criminalidade violenta.

\section{REFERÊNCIAS}

BONDARUK, Roberson. A prevenção do crime através do desenho urbano. Curitiba: Edição do Autor, 2007.

CALDEIRA, Teresa. Cidade de muros: crime, segregação e cidadania em São Paulo. 2. ed. São Paulo: Edusp, 2000.

FOUCAULT, Michel. Vigiar e punir: nascimento da prisão; tradução de Raquel Ramalhete. Petrópolis, Vozes, 1987.

IBGE, Instituto Brasileiro de Geografia e Estatística. Regiões de influência das cidades. Coordenação de Geografia. Disponível em:

<http://www.ibge.gov.br/home/geociencias/geografia/regic.shtm?c=7>. Acesso em: $23 \mathrm{de}$ mar. 2007.

IBGE, Instituto Brasileiro de Geografia e Estatística. Censo 2010. Disponível em: <http://censo2010.ibge.gov.br>. Acesso em: 25 de mar. 2010.

JACOBS, Jane. Morte e vida de grandes cidades. São Paulo: Martins Fontes, 2000.

LIRA, Pablo. Geografia do crime e Arquitetura do medo: uma análise da criminalidade violenta e das instâncias urbanas. Vitória: Gráfica e Editora GSA, 2014.

LYRA, Ana Paula. Estratégias socioambientais para inibição de ações antissociais: um estudo de caso do Bairro Bento Ferreira e seu entorno, Vitória, ES. Projeto de Pesquisa Institucional. Vila Velha: UVV/FAPES. 2015.

NEWMAN, Oscar. Creating defensible space. Washington, EUA: Department of Housing and Urban Development Office of Policy Development and Research. Disponível em: <http://www.huduser.gov/publications/pdf/def.pdf>. Acesso em: 22 de mar. 2016.

SANTOS NEVES, João Marques dos. Arquitetura do Medo e seus reflexos no espaço urbano de Feira de Santana: o caso do Bairro Santo Antônio dos Prazeres. Dissetação (Programa de Pós-Graduação em Arquitetura e Urbanismo), Faculdade de Arquitetura da Universidade Federal da Bahia, Salvador. 2016. 